\title{
Mehmet Harman
}

\section{Kutanöz Leishmaniasis}

\section{Cutaneous Leishmaniasis}

\section{Öz}

Leishmaniasis, leishmania türlerinin neden olduğu ve enfekte dişi tatarcıkların ısırmasıyla insanlara bulaşan bir dizi hastalığı tanımlamaktadır. Hastalığın kutanöz, mukokutanöz ve visseral olmak üzere üç ana formu bulunmaktadır. Dünya Sağlık Örgütü verilerine göre, tüm dünyada toplam 98 ülkede yaklaşık 12 milyon insan leishmaniasise yakalanmış durumda olup, 350 milyon kişinin ise risk altında yaşadığı bildirilmektedir. Her yıl bu rakamlara 2 milyon yeni olgunun katıldığı, bu olguların yaklaşık dörtte üçünün kutanöz leishmaniasis (KL) olduğu tahmin edilmektedir. Bilimsel ve medikal topluluklar tarafından 20. yüzyılda ve 21. yüzyılın başlarında leishmaniasis hakkında çok şey öğrenilmesine rağmen hastalığın kontrolü ve idaresi hala zordur. Bu makalede hastalığın en yaygın formu olan KL'nin, özellikle epidemiyolojisi ve tedavisine odaklanılmaktadır.

Anahtar kelimeler: Leishmaniasis, kutanöz, epidemiyoloji, etiyopatogenez, tedavi, korunma

\section{Abstract}

Leishmaniasis is used to describe a spectrum of diseases caused by the parasitic protozoa leishmania spp. and transmitted by infected female sandflies. There are three main forms of the disease; cutaneous, mucocutaneous, and visceral. According to the World Health Organization, almost 12 million people from 98 countries worldwide are currently infected with leishmaniasis, while 350 million people are at risk. It was reported that 2 million new cases are diagnosed every year, with three-fourth are cutaneous leishmaniasis $(\mathrm{CL})$ cases. The scientific and medical communities have learnt a lot about $\mathrm{CL}$ during the $20^{\text {th }}$ and early $21^{\text {st }}$ centuries. However, the management and control of the disease remains a difficult task. This article was focused on the most common form of the disease, cutaneous leishmaniasis, and especially its epidemiological aspects and treatment.

Keywords: Leishmaniasis, cutaneous, epidemiology, etiopathogenesis, treatment, prevention

Dicle Üniversitesi Tıp Fakültesi, Dermatoloji Anabilim Dalı, Diyarbakır, Türkiye

Yazışma Adresi/
Correspondence:
Mehmet Harman,
Dicle Üniversitesi Tıp Fakültesi,
Dermatoloji Anabilim Dall,
Diyarbakır, Türkiye
Tel.: +90 412 248 80 01/4214
E-posta: mharman@dicle.edu.tr
Gelis Tarihi/Submitted: 28.10 .2015
Kabul Tarihi/Accepted: 04.11 .2015

@Telif Hakkı 2015 Türk Dermatoloji Derneği Makale metnine www. turkdermatolojidergisi.com web sayfasından ulaşılabilir.

@Copyright 2015 by Turkish Society of Dermatology - Available on-line at www.turkdermatolojidergisi.com

\section{Giriş}

Leishmaniasis, leishmania protozoan mikroorganizmalarının neden olduğu, vektör dişi kum sineğinin (yakarca, tatarcık) ısırması ile bulaşan hastalık kompleksidir. Enfekte insanlar, köpekler ve kemirgenler rezervuar konaklardır. Leishmania türüne ve konağın immün yanıtına göre enfeksiyon kutanöz, mukokutanöz veya visseral hastalıkla sonuçlanır (1).

Leishmaniasisten sorumlu mikroorganizma yüz yıldan daha uzun süredir keşfedilmesine karşın leishmaniasis özellikle gelişmekte olan ülkeler başta olmak üzere pek çok ülkede hala önemli bir halk sağlığı problemi olarak devam etmektedir. Gerek tedavisi, gerekse kontrolünün zorluğu nedeniyle, paraziter hastalıklar içinde sıtmadan sonra önem bakımından ikinci sırada gelmektedir (2). Hastaların büyük çoğunluğu yoksulluk ve kırsal alanlarda yaşama nedeniyle tanı ve tedavi olanaklarından yararlanamamaktadırlar (3).

Dünya Sağlık Örgütü (DSÖ) verilerine göre tüm dünyada toplam 98 ülkede yaklaşık 12 milyon insan leishmaniasise yakalanmış durumda olup, 350 milyon kişinin ise risk altında yaşadığı bildirilmektedir. Her yıl bu rakamlara 2 milyon yeni olgunun katıldığı, bu olguların yaklaşık 1,5 milyonunun kutanöz leishmaniasis (KL) olduğu tahmin edilmektedir (2). Türkiye KL'nin endemik olduğu ülkelerden biridir. Türkiye'nin bulunduğu bölgede, özellikle İran ve Suriye gibi komşularında KL halen önemli bir halk 
sağlığı sorunudur (4). Suriye'de yaşanan savaştan kaçarak ülkemize sığınan ve sayıları 2 milyonu aşan mülteciler başta $\mathrm{KL}$ olmak üzere birçok bulaşıcı hastalığın ülkemize taşınması riskini ortaya çıkarmıştır. Türkiye'de 2013 yılında 2,268 yerli ve 2000 'den fazla Suriyeli KL olgusu rapor edilmiştir (5).

Lezyonların ağrısız olması, yaklaşık bir yıl içinde iz bırakarak kendiliğinden iyileşebilmesi, sistemik komplikasyonlara ve ölüme neden olmaması hastalığın toplum tarafından kabul edilmesine yol açmıştır. Ancak aktif lezyonu veya sikatrisi olanlarda depresyon, anksiyete ve yaşam kalitesinde azalma gibi sosyal ve psikolojik sorunlara yol açmaktadır (6).

Leishmaniasiste mevcut tedaviler idealden uzaktır. ilaç geliştirilmesi ve keşfi açısından leishmaniasis en ihmal edilmiş hastalıklardan biridir (7). Mevcut antileishmanial ilaçların çoğu yüksek derecede toksiktir, direnç sorunu vardır ve sistemik tedavi için hastaneye yatış gerekir (8).

\section{Epidemiyoloji}

KL'nin görülme sıklığı bölgenin ekolojik, iklim, vektör ve rezervuarların coğrafik dağılımıyla yakından ilişkilidir (9). Hem konağın yaşam ve davranış biçimleri, hem de vektörün üreme ve yaşam özellikleri KL epidemiyolojisinde önem taşımaktadır. Endemik bölgeden endemik olmayan bölgeye göçlerle gelen enfekte kişilerin uygun vektör ve çevre-iklim şartları varsa hastalığı o bölgeye taşımaları mümkündür. Aynı zamanda da enfekte olmayan kişiler endemik bölgeye geldiklerinde bölgenin yerleşik insanlarından daha fazla enfeksiyon riskine sahip olmaktadırlar. Bu nedenlerle KL epidemileri sıklıkla göçmenlerde ve duyarlı olmayan kişilerin endemik bölgelere gelmesi ile ortaya çıkar (10). Endemik bölgelerin çoğunda leishmaniasis fokal odakları vardır. Bu alanlar vektörü, paraziti ve rezervuar konağı etkileyen mikro ekolojik durumlarla ilişkilidir (3).

Hastalığın dağılım ve yayılımı ekonomik durum, davranış ve çevre değişiklikleri ile ilişkilidir. Yeni yerleşim yerleri, orman alanlarına yerleşimler, ormanların yok edilmesi, kırsal alanlardan şehirlere göç, hızlı ve plansız şehirleşme, köpek ve kemirgen popülasyonunda artış, insektisit kullanımında azalma, immünsüprese konak sayısında artış, barajların inşası, yeni sulama projeleri, başta savaş ve doğal afet olmak üzere çeşitli nedenlerle göçler hastalığın yayılmasında önemli rol oynamaktadır. Küresel ısınma ve buna bağlı iklim değişikliklerinin etkisiyle vektör canlıların popülasyonlarında artış olacağı, üreme ve yaşam alanlarının deniz seviyesinden daha yükseklere ve kuzey enlemlere doğru genişleyeceği düşünülmektedir $(2,11)$. KL iklime duyarlı bir hastalık olup; sıcaklık, yağış ve nem oranlarındaki değişimler; dağılımlarını, hayatta kalma sürelerini ve popülasyon büyüklüklerini değiştirerek tatarcıklara ve rezervuar konaklara etki edebilir (3). Çarpık kentleşme ve kentlere göç sonucu rodent rezervuar konakların yoğun bulunduğu alanlarda varoşların oluşması bu alanlarda leishmaniasis insidansında artışa neden olmuştur (2).

Antroponotik tip enfeksiyonlarda epidemi riski daha yüksektir. Epidemiler vektör habitatındaki değişiklikler, kitleler halinde insan hareketleri (mevsimsel, savaş, doğal affet gibi nedenlerle) ve malnutrisyon gibi immüniteyi azaltan durumlarla ilişkilidir. Non-endemik alanlardaki epidemilerde çocuklar ve erişkinler daha çok etkilenir. Endemik alanlarda ise daha çok çocuklar etkilenir, erişkinlerin çoğu daha önce subklinik veya klinik olarak hastalığı geçirdiklerinden bağışıktırlar (3).

DSÖ leishmaniasisin yoksul ülkelerde ve bulaştan sorumlu tatarcıkların kontrolünün iyi yapılamadığı bölgelerde gittikçe arttığını ve KL'nin yıllık insidansının yaklaşık 1,5 milyon olduğunu bildirmektedir (12). KL olgularının \%90'ından fazlasının Afganistan, Pakistan, Suriye, Suudi Arabistan, Cezayir, İran, Brezilya ve Peru'da ortaya çıktığı belirtilmektedir (4). Hastaların çoğunluğunun kırsal alanlarda yaşaması, yoksulluk, hastalığın toplum tarafından önemsenmemesi ve kabul edilmesi gibi nedenlerle hastaların çoğu tanı ve tedavi amacıyla tıbbi merkezlere başvurmamakta ve birçoğunun sağlık otoritelerine bildirimi yapılmamaktadır. Gerçek olgu sayısının bildirilenin 3-5 katı olduğu tahmin edilmektedir. Dünyada KL olgularının en çok bildirildiği ülkelerde bildirime göre ve tahmini insidanslar Tablo 1'de belirtilmiştir (13).

Hastalık yüzyıllardır ülkemizde tanınmakta olup; Urfa çıbanı, Antep çıbanı, yıl yarası, Halep çıbanı, Şark çıbanı gibi değişik adlarla bilinmektedir. Ülkemizde 1950 öncesi Güneydoğu Anadolu Bölgesi başta olmak üzere yaygın şekilde görülmekteyken, 1950 sonrası sıtma savaşında yoğun dikloro difenil trikloroethan (DDT) kullanılmasıyla enfekte kum sineği vektör popülasyonlarının azalması gibi nedenlerle hastalık Güneydoğu Anadolu bölgesinde sınırlı kalmış ve diğer bölgelerde de sporadik bir görünüm almıştır. Ancak sonraki yıllarda gerek mücadele çalışmalarının aksatılması, gerekse vektörlerin insektisitlere karşı direnç geliştirmesi, Güneydoğu Anadolu Projesi kapsamında yapılan barajlar ve sulama sistemlerinin iklim ve ekosistem üzerindeki etkileri, vektör mücadelesinin yetersizliği, tedavide karşılaşılan zorluklar ve köyden kente göçler nedeniyle olgu sayılarında tekrar artış olmuştur $(14,15)$. Özellikle 1980 sonrası Şanlıurfa'da ve ardından 1985 sonrası Çukurova'da KL olgu sayılarında büyük artışlar görülmüştür (16). Suriye'deki iç savaş nedeniyle

Tablo 1. Kutanöz leishmaniasisin dünyada en çok

\begin{tabular}{|c|c|c|c|}
\hline Ülke & $\begin{array}{l}\text { Bildirilmiş } \\
\text { Olguların } \\
\text { Ortalama } \\
\text { Yıllık Sayısı }\end{array}$ & $\begin{array}{l}\text { Bildirim } \\
\text { Yilları }\end{array}$ & $\begin{array}{l}\text { Tahmini Yıllık } \\
\text { Olgu Sayısı }\end{array}$ \\
\hline Brezilya & 26008 & $2003-2007$ & $72,800-119,600$ \\
\hline Kolombiya & 17420 & 2005-2009 & $48,800-80,100$ \\
\hline Peru & 6405 & 2004-2008 & $17,900-29,500$ \\
\hline Cezayir & 44050 & 2004-2008 & $123,300-202,600$ \\
\hline Suriye & 22882 & 2004-2008 & $64,100-105,300$ \\
\hline Tunus & 7631 & 2004-2008 & $21,400-35,100$ \\
\hline Türkiye & 2465 & 2003-2007 & $6,900-11,300$ \\
\hline Afganistan & 22620 & $2003-2007$ & $113,100-226,300$ \\
\hline İran & 24630 & 2004-2008 & $69,000-113,300$ \\
\hline Irak & 1655 & 2004-2008 & $8,300-16,500$ \\
\hline Pakistan & 7752 & 2004-2008 & $21,700-35,700$ \\
\hline Suudi Arabistan & 3445 & 2004-2008 & $9,600-15,800$ \\
\hline
\end{tabular}


ülkemize göç eden mültecilerde hastalığın sıklıkla görülmesi nedeniyle özellikle Güneydoğu Anadolu illerimizde hastalık önemli bir boyut kazanmıştır (17-19). Bölgeden gerek mevsimlik gerekse kalıcı göçlerin etkisiyle, ulaşım ve seyahat olanaklarının da kolaylaşmasıyla endemik olmayan diğer bazı illerde de olgular görülmeye başlanmıştır (11).

Türkiye'de KL açısından Güneydoğu Anadolu bölgesi ve Akdeniz bölgesinin Çukurova yöresi endemik olup, Sağlık Bakanlığı verilerine göre 1988-2010 yılları arasında ülke genelinde saptanan toplam 50381 olgunun yaklaşık yarısı Şanlıurfa ilinden olmak üzere \%96'sı Şanlıurfa, Adana, Osmaniye, Hatay, Diyarbakır, İçel ve Kahramanmaraş illerinden bildirilmiştir. Şanlıurfa ilini sırasıyla Adana, Osmaniye, Hatay, Diyarbakır, Içel, Kahramanmaraş, Antalya, Aydın, Kayseri, Niğde, Muş ve bildirim yapan diğer 47 il takip etmektedir (11). Türkiye'de 1990-2014 yılları arasındaki KL istatistikleri incelendiğinde yeni olgu sayılarının 1994 ve 2004 yıllarında zirve yaptığı görülmektedir (Şekil 1).

Son yıllarda Türkiye'nin Batı ve Kuzey bölgeleri gibi nonendemik bölgelerinden bildirilen olgular başta Suriye olmak üzere komşu ülkelerden gelen mültecilerden ve/veya iş-eğitim amacıyla endemik illerimizden gelen kişilerden oluşmaktadır. KL belirli bölgelerde yoğunlaşmakla birlikte hastalığın kuluçka süresinin uzun olması ve lezyonların yavaş bir seyir göstermesi hastalığın endemik olduğu bölgeler dışında da görülmesine ve tanı konulmasına neden olmaktadır. Endemik bölgelere seyahatlerin artması ve askeri operasyonlar nedeniyle 1990'lı yıllardan itibaren gelişmiş ülkelerde KL olgu sayılarında artış olmuştur $(20,21)$. Her yaşta görülen bir hastalık olmakla birlikte, endemik bölgelerde çocuk yaş gruplarında daha fazla görülmektedir (14-16,2224).

\section{Etyopatogenez}

Leishmania prototozoan mikroorganizmaları ilk kez 1903 yılında Leishman ve Donovan tarafından saptandı. Günümüzde en az 20 türünün insanlarda hastalık yaptığı bilinmektedir. Bazıları visseral, bazıları kutanöz, bazıları

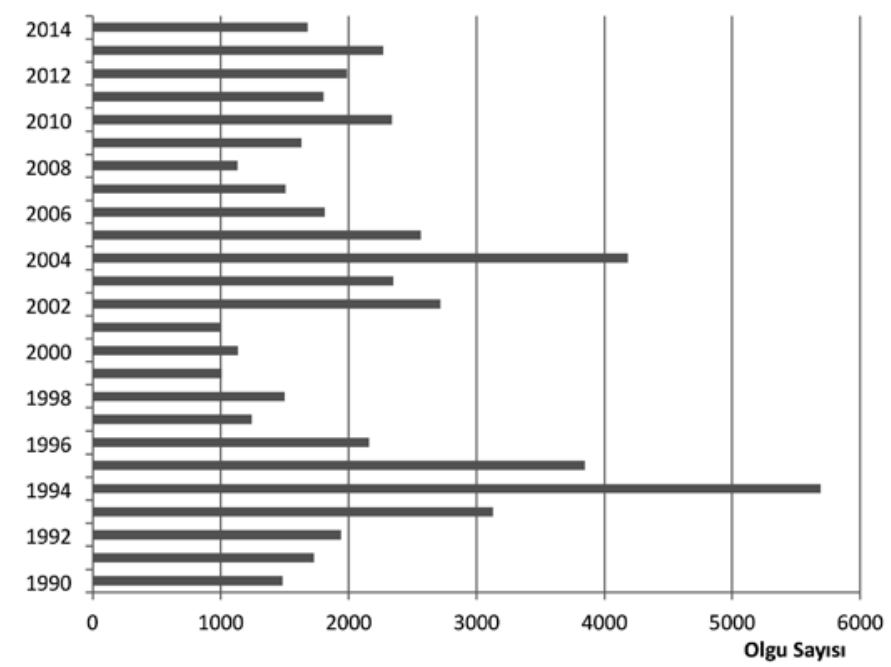

Şekil 1. Türkiye'de 1990-2014 yıllarında bildirilen 53,847 kutanöz leishmaniasis olgusunun yıllara göre dağılımı mukokutanöz, bazıları ise hem kutanöz hem de visseral hastalığa neden olurlar (2).

Eski Dünya'da KL'ye en sık L. tropica ve L. major, daha az sıklıkta L. infantum ve L. aethiopica neden olur. L. donovaninin neden olduğu lokalize KL olguları bildirilmiştir (25). Son zamanlarda ülkemizde $\mathrm{KL}$ etkeni olarak $\mathrm{L}$. major ve $\mathrm{L}$. donovaninin varlığı da gösterilmiştir (26). Türkiye'nin komşuları olan Suriye, Irak ve İran'da L. majorün endemik olduğu bilinmektedir. Yeni Dünya'da KL Meksika, Orta ve Güney Amerika'da endemik olup, en sık L. braziliensis ve L. mexicana etkendir. Mukokutanöz leishmaniasis (MKL) ise Güney Amerika'da endemik olup, L. braziliensis etkendir. MKL olgularının \%90' Bolivya, Brezilya ve Peru'dan bildirilmektedir (2).

Vektör Eski Dünya'da Phlebotomus, Yeni Dünya'da ise Lutzomyia dişi kum sinekleridir. Kum sinekleri halk arasında tatarcık, yakarca, üvez gibi isimlerle adlandırılmaktadır (27). Gün batımı ile gün doğumu arasında aktivite gösteren ergin kum sineklerinin sadece dişileri yumurtalarının gelişimi için insan ve diğer memeli canlılardan kan emerler (2). Ergin kum sinekleri gündüzleri ise; yüksek nem oranına sahip, loş veya karanlık alanlarda, rüzgardan fazla etkilenmeyen ağaç kovukları, ahır, gübre yığınları, mağaralar, duvar yarık ve çatlakları, elbise dolaplarında, tuvalet ve banyo köşelerinde saklanırlar. Yuvalarında rahatsız edildiklerinde gündüz de ısırırlar (1). Hastalığa vektörlük yapan erişkin diş̧i kum sineklerinin aktiviteleri ilkbaharın son dönemleri ve yaz başlangıcında başlar ve havalar soğuyuncaya kadar devam eder. İnkübasyon dönemine bağlı olarak da lezyonlar daha çok Ekim ayından Şubat ayına kadar olan dönemde ortaya çıkmaktadır $(11,28)$.

Dişi kum sinekleri, KL etkeni leishmania parazitleriyle enfekte olmuş insan veya diğer memelilerden (köpekgiller ve kemirgenler) kan emdiğinde parazitin, makrofajlar içinde veya serbest halde bulunan amastigot formlarını da alırlar. Bu amastigot formlar kum sineğinin orta bağırsağında sıcaklık ve PH'nın etkisiyle promastigot formuna dönüşerek çoğalırlar. Promastigotlar birkaç farklı morfolojik form sonrası enfektif metasiklik promastigot formuna dönüşerek sineğin ön bağırsağına hareket ederler. Kum sineği insan veya memeli diğer konaklardan kan emdiğinde bu enfektif promastigotlar deriye inoküle olurlar. Dermiste makrofajlar tarafından fagosite edilen parazit, kamçısını kaybederek amastigot haline dönüşür. Makrofaj içinde ikiye bölünerek çoğalan amastigotlar makrofajları patlatarak serbest hale geçer ve diğer makrofajları enfekte ederler (29).

\section{Klinik}

$\mathrm{KL}$ oluşumunu ve iyileşme sürecini konak ve parazitin özellikleri belirlemektedir. Leishmaniasis genel olarak bağışıklık sistemi ile çok yakından ilgili bir enfeksiyon olduğu için paraziti alan birçok kişide parazit elimine edilir ve klinik enfeksiyon gelişmez (30).

KL lezyonu enfekte dişi kum sineğinin ısırdığı yüz, boyun ve ekstremiteler gibi giysiyle örtülmeyen alanlarında eritemli bir papül olarak başlar. Yavaş bir şekilde büyüyerek haftalaraylar sonra merkezinde sıkıca yapışık kabukla kaplı ülser bulunan nodül veya plağa dönüşür. Ülsere lezyon üzerindeki sıkıca yapışık sert kabuk kaldırıldığında kabuğun alt yüzünde 
çiviye benzer çıkıntılar görülür, bunlara Hulusi Behçet'in "çivi belirtisi" adı verilir (1). Çok sayıda ısırma durumunda çok sayıda lezyon olabilir ve bu lezyonlar genellikle aynı özelliktedirler. Lenfatik yayılma sonucu nodüler lenfanjit şeklinde sattelit lezyonlarla karakterize sporotrikoza benzeyen lezyonlar tanımlanmıştır. Sekonder bakteriyel enfeksiyon olmadıkça lezyonlar ağrısızdır. L. tropicanın neden olduğu KL antroponotik veya kuru tip olarak bilinir, kırsal olmayan alanlarda görülür. Lezyonlar yavaş seyir göstererek geç ülserleşir. Sıklıkla çok sayıda, kuru, ülsere nodül ve plaklar olur (Resim 1). Lezyonlar bir yıl veya daha uzun sürede yerinde kötü sikatris bırakarak iyileşir. İnkübasyon periyodu genellikle 2-8 aydır. L. majorün neden olduğu $\mathrm{KL}$ zoonotik veya yaş tip olarak bilinir, kırsal alanlarda görülür. Hızlı seyir gösterir. Lezyonlar şiddetli inflamme ve ülsere olup, 2-8 ayda iyileşirler. Sıklıkla çok sayıda olan lezyonlar büyük, kötü görünümlü veya fonksiyon bozukluğu yapabilen sikatris bırakabilir (Resim 2). L. infantumun neden olduğu KL Akdeniz havzasında görülür. L. infantum çocuklarda visseral leishmaniasise de neden olabilir (3).

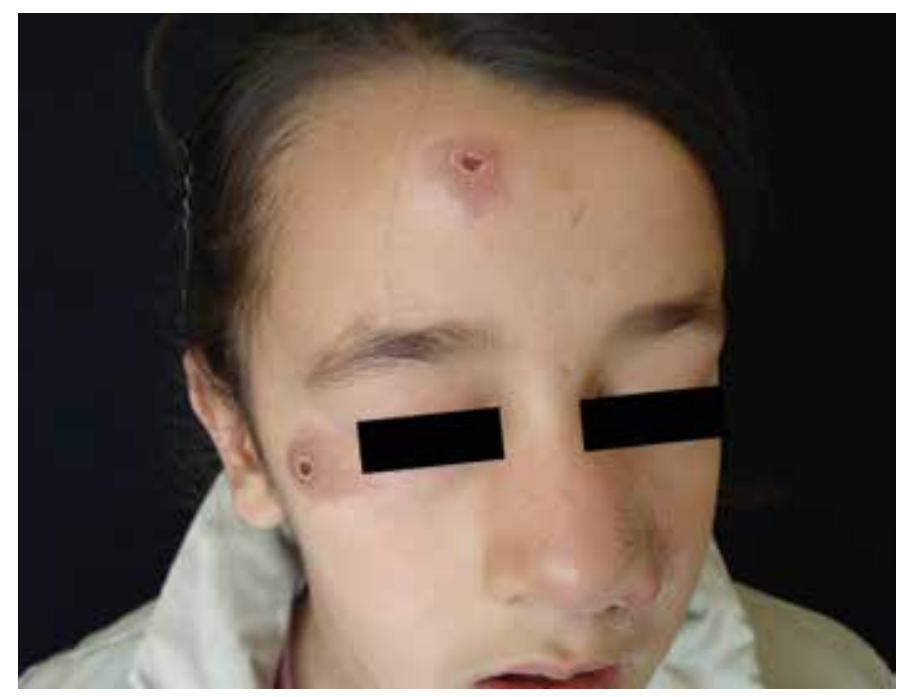

Resim 1. Kuru tip kutanöz leishmaniasis

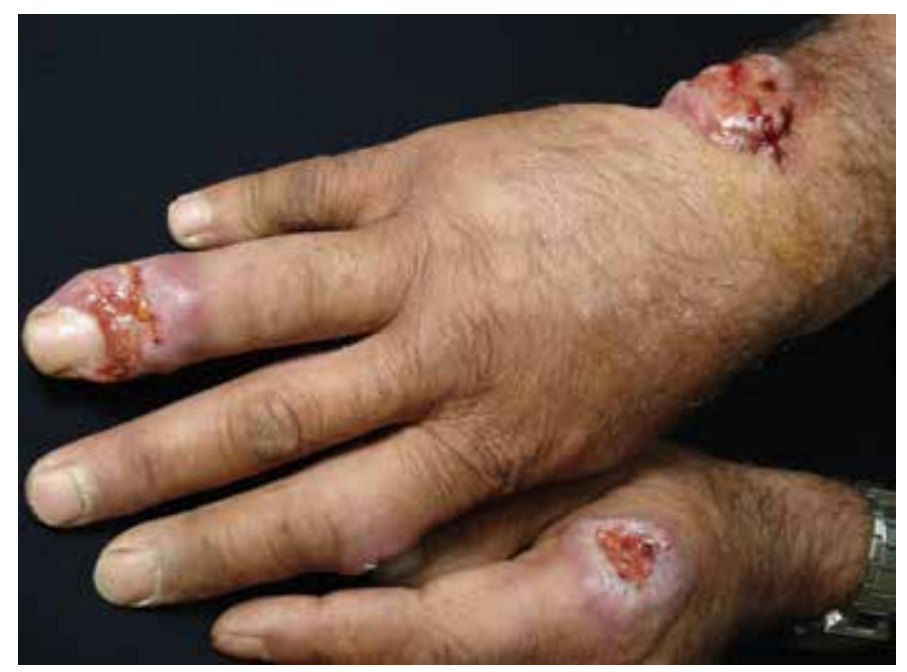

Resim 2. Yaş tip kutanöz leishmaniasis
Akut KL lezyonları genellikle 1-2 yıl içinde yerinde çökük bir sikatris bırakarak iyileşirler. Iki yıldan daha uzun süren lezyonlar varsa kronik KL olarak sınıflandırılır (3). Kronik KL primer lezyonların iki yıldan daha uzun süre devam etmesi (Lupoid leishmaniasis) veya iyileşmiş primer lezyonun sikatrisinin üzerinde-kenarında aylar-yıllar sonra reaktivasyon olması (Rezidivan leishmaniasis) şeklinde olabilir (Resim 3). Antroponotik, daha nadiren zoonotik KL lupus vulgarise benzeyen lupoid leishmaniasise dönüşebilir. Rezidivan KL'ye hemen daima L. tropica neden olur. Kronik KL yıllarca devam edebilir. Lezyonda amastigotların az olması tanıda gecikmeye neden olabilir (31).

Özellikle immünsüprese kişilerde kutanöz hastalık dissemine (diffüz KL) olabilir. Bu form lepramatöz lepra ile karıştırılabilir. Eski Dünya leishmaniasisinde mukozal lezyonlar nadir olup, yaşlı veya immünsüprese kişilerde mukozal yayılma olabilir (3).

\section{Tanı}

$\mathrm{KL}$ tanısı için endemik bölgelerde yaşama veya endemik bölgeye seyahat öyküsü olan ve hastalığı düşündüren klinik bulguya sahip hastalarda parazitolojik doğrulamanın yapılması gerekmektedir (32). Yayma için materyal sekonder enfekte olmamış, en yeni/aktif lezyondan alınmalıdır. Giemsa ile boyanmış yaymaların mikroskobik incelemesinde amastigotların görülmesi ile tanı doğrulanır (Resim 4). Erken lezyonlarda amastigotlar çok, geç ve sekonder enfekte lezyonlarda amastigotlar az sayıdadır. Kronik olgularda amastigotlar çok az sayıda olduğundan, saptamak zordur (33).

Ayrıca tanıda; bası smear yöntemi, ince iğne aspiratı yöntemi, kültür, insizyonel deri biyopsisi ve biyopsi materyalinde veya deri aspiratlarından gönderilen örneklerle gerçekleştirilen polimeraz zincirleme tepkimesi (PCR) yöntemi kullanılmaktadır (32). Leishmania türlerinin tayininde günümüzde en çok isoenzim elektroforez ve PCR olmak üzere iki yöntem kullanılmaktadır. Leishmania kültürü için NicolleNovy-MacNeal (NNN) veya modifiye NNN besi yerleri kullanılır.

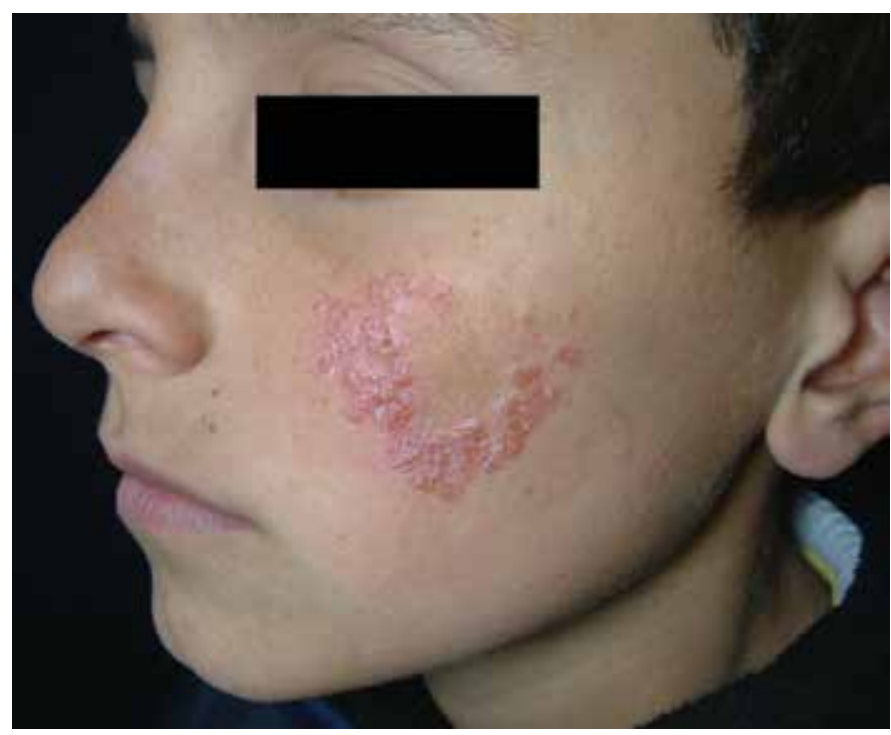

Resim 3. Rezidivan kutanöz leishmaniasis 
Kültürlerden genellikle bir hafta içerisinde pozitif sonuç alınır. Normal şartlarda pozitif örneklerin yaklaşık \%70'inde üreme olmaktadır. Bakteriyel kontaminasyon olduğunda leishmanialar üreyemezler. Bu nedenle besi yerlerine aseptik şartlarda ekim yapılmalıdır (34).

Histopatolojik olarak KL'de dermiste histiyositler, lenfositler ve plazma hücrelerinden oluşmuş inflamatuvar infiltrat görülür. Makrofajlar içinde ve dışında amastigotlar bulunur. Zamanla epiteloid hücreler ve dev hücrelerin sayısı artar, amastigot sayısı azalır. Kronik lezyonlarda granülomatöz dermatit tablosu vardır (33).

KL'nin klinik spektrumu oldukça geniş olup, birçok diğer deri hastalığını taklit edebilir (31).

\section{Tedavi}

$\mathrm{KL}$ hayatı tehdit eden ve ciddi problemlere neden olabilen bir hastalık değildir, genellikle spontan iyileşme gözlenir. Bu nedenle her hastayı tedavi etmek gerekmez. Tedavinin yararları iyileşmeyi hızlandırması, tekrarlama olasılığını azaltması, sikatris oluşumunu önlemesi/azaltması, hastalığın yayılma riskini (dissemine kutanöz, mukozal) ve özellikle antroponotik KL'de enfeksiyöz kaynağı azaltmasıdır. KL'de kullanılacak ilaç veya tedavi yaklaşımı hayatı tehdit edecek komplikasyonlara neden olmamalıdır. Hastalığın tanısı doğrulanmadan tedaviye başlanmamalıdır. Tedavi kararında her hasta için risk-fayda oranı dikkate alınmalıdır. Lokal, sistemik ve fiziksel olmak üzere çeşitli tedavi yöntemleri $\mathrm{KL}$ tedavisinde kullanılmış ve denenmiştir. Parazitin türü, coğrafik bölge ve hastanın immünolojik durumu tedavinin etkinliğini etkiler (35).

Komplike olmayan $\mathrm{KL}$ olgularında primer tedavi yaklaşımı lokal tedavidir. Primer olarak L. tropica ve L. infantumun neden olduğu komplike olmayan KL'li olgularda yara bakımı ve lokal tedavi etkili bulunmuştur (36). Sekonder bakteriyel enfeksiyon ciddi komplikasyonlara neden olabileceğinden lezyonu temiz tutmak önemlidir. Tüm hastalarda lezyonlar temiz su ve sabunla yıkanıp steril gazıı bezle kapatılmalıdır. Gazlı bez haftada 3-4 kez değiştirilmelidir. Bu iyileşmeyi kolaylaştırır ve yapışık kabuk oluşumunu önler. Bakteriyel süperenfeksiyon varsa amoksisilin-klavulanik asit gibi

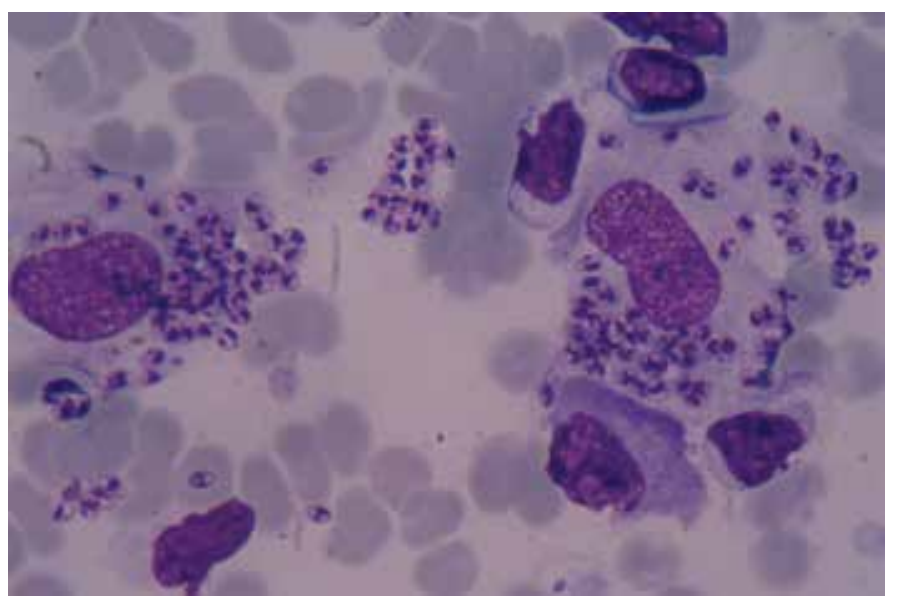

Resim 4. Yaymada makrofajlar içinde ve dışında amastigotlar (Giemsa x1000) streptokok ve stafilokoklara etkili oral bir antibiyotik başlanmalıdır. Bu olgular intralezyonel (IL) antimon bileşiği ile tedavi edilecekse bakteriyel süperenfeksiyon tedavi edildikten sonra tedaviye başlanmalıdır (2).

$\mathrm{KL}$ tedavisinde en fazla tercih edilen ilaçlar pentavalent antimon (SbV) bileşikleridir. Bu bileşikler 1940'lı yıllardan beri leishmaniasis tedavisinin temelini oluşturmaktadır (2). Pentavalent antimon bileşikleri arasında en iyi bilinenler; meglumine antimonate (Glucantime ${ }^{\circledast}$ ) ve sodium stibogluconatedır (Pentostam ${ }^{\oplus}$ ) (37). Bu ilaçlar lezyon içine veya sistemik olarak uygulanabilmektedirler. Sistemik tedavi dozlarının toksisite riski nedeniyle Türkiye'de en fazla tercih edilen yöntem IL meglumine antimonate tedavisidir (12). Ancak lezyonun bulunduğu bölge, lezyon sayısı, büyüklüğü ve durumu IL tedaviye uygun değilse veya İL tedaviye cevap alınamamışsa sistemik tedavi de uygulanabilmektedir (38).

Komplike olmayan KL'de uygun yerleşimli papüller ve ülserleşmemiş nodüler lezyonlarda IL SbV tedavisi tercih edilmelidir. Bu tedavi kriyoterapi ile kombine edilebilir (2). Her 3-7 günde bir olmak üzere toplam 5-8 kez her seferinde lezyon solana kadar SbV IL yapılır. Lokal alerjik reaksiyon, ağrı, ödem ve geçici eritem gibi istenmeyen durumlar gelişebilir. İ SbV tedavisi parmaklar, kulak, burun, göz kapağı ve dudağa uygulanmamalıdır (39-40). KL tedavisinde IL meglumin antimonat (MA) tedavisi í sodium stibogluconate (SSG) tedavisinegöre daha etkili bulunmuştur (41).Türkiye'de yapılan iki çalışmada IL MA tedavisi ile $\% 82,8$ ve $\% 97$ oranlarında iyileşme bildirilmiştir $(28,41)$. Intra lezyonel antimon tedavisi kriyoterapi ile kombine edilecekse I I tedaviden önce tek seans kriyoterapi uygulanması yeterlidir (2).

Kriyoterapinin etkinliği klinik çalışmalarda \%53 ile 100 arasında değişen oranlarda bildirilmiştir. Kriyoterapi ve takiben yapılan İL SbV şeklindeki lokal tedavi daha etkili bulunmuştur $(42,43)$. Küçük, non-ülsere yeni lezyonlarda tek başına kriyoterapi yapılabilir. Lezyon etrafında da 1-2 $\mathrm{mm}$ buz halkası oluşacak şekilde $15-20$ saniye likit nitrojen uygulanmasını takiben 20-60 saniyelik aradan sonra tekrar 15-20 saniye likit nitrojen uygulanması şeklinde uygulama önerilmektedir (44). Bu uygulama iyileşme olana kadar üç haftada bir tekrarlanabilir. Kriyoterapi eritem, ödem, bül oluşumu, kalıcı pigment değişiklikleri ve sikatris oluşumuna neden olabilir.

Termoterapi az sayıda, küçük ve göz kapağı, burun, dudak, kulak lokalizasyonlu olmayan lezyonlarda kriyoterapiye alternatif bir tedavi olarak kullanılabilir. Amerika Birleşik Devletleri'nde (ABD) bu amaçla kullanım için onay almış termoterapi cihazı (ThermoMed) vardır. Bu cihaz ile yapılan ISI tedavisinden 2-3 ay sonra \%53 ile 73 arasında değişen klinik iyileşme oranları bildirilmiştir $(45,46)$. Lezyona ve $1-2$ $\mathrm{mm}$ etrafındaki normal deriye 30 saniye 50 santigrad derece ISI uygulanır. İyileşme olana kadar haftalık intervallerle bu uygulama üç kez tekrarlanabilir. Uygulama ağrılı olduğundan lokal anestezi gerekir. Termoterapi mukozal ve lenfokutanöz yayılma potansiyeli olan lezyonlarda kullanılmamalıdır. Ayrıca yüzeyel sinirler, kıkırdak, burun, dudak ve göz kapağı üzerine doğrudan uygulanmamalıdır. Ilave olarak termoterapi ve kriyoterapi sistemik tedaviden sonra iyileşmeyen rezidüel lezyonların tedavisinde kullanılabilir. Ayrıca gebe ve emziren kadınlarda da her iki tedavi de uygundur. 
Fotodinamik tedavi reaktif oksijen ürünleri oluşturarak dokuda harabiyete neden olur. Bu amaçla hedef dokuda seçici olarak biriken bir foto duyarlandırıcı (5-aminolaevulinic acid gibi) alındıktan sonra ışılama yapılır. Nispeten yeni olan bu tedavi yöntemine ilişkin veriler sınırlıdır. Eski Dünya KL'li olgularda tedaviden 2 ay sonra \%93 oranında tam klinik iyileşme bildirilmiştir (47).

Topikal paromomycin L. major lezyonlarında kullanılabilir (48). Paromomycin \%15 ve methylbenzethonium $\% 12$ içeren merhem (Leishcutan ${ }^{\oplus}$ ) L. majorlü 67 olgunun \%87'sinde etkili bulunmuştur. Lokal ağrı, deri irritasyonu ve ödem gibi istenmeyen reaksiyonlar gelişebilir (49).

Yüz ve kulak gibi kozmetik açıdan önemli yerlerdeki lezyonlarda, lokal tedaviden sonra 2-3 ayda iyileşmeyen lezyonlarda, eklemler üzerindeki lezyonlarda, el ve ayaktaki lezyonlarda, yayılma eğilimi olan lezyonlarda, immünsüprese hastalardaki lezyonlarda, çok sayıda (4'ten fazla) lezyonlarda, mukozal lezyonlarda ve $4 \mathrm{~cm}$ 'den büyük lezyonlarda ve nodüler lenfanjittin geliştiği olgularda sistemik tedavi önerilmektedir (2).

\section{Kutanöz Leishmaniasiste Tedavi Protokolü (3)}

1. L. majorün neden olduğu veya involüsyon gösteren 4 cm'den küçük boyutlardaki 4'ten az sayıdaki lezyonlarda lezyon/lezyonların kozmetik ve fonksiyonel bozukluk oluşturma potansiyeli yoksa ve hastada immün bozukluk ve kontrolsüz diyabet yoksa temiz su sabunla yıkama ve kapalı pansuman yapılarak izlenir. Altı ay içinde iyileşme olmazsa antileishmanial tedaviye geçilir.

2. Birinci durumdaki iyileşmeyen lezyonlarda, $4 \mathrm{~cm}$ 'den küçük boyutta ve 4 'ten az sayıdaki lezyonlarda, lezyonlar lokal tedavi için uygun yerdeyse, L. tropica veya L. infantuma bağlı bir veya birden çok lezyon varsa, hastada immün bozukluk ve kontrolsüz diyabet yoksa aşağıdaki seçeneklerden biri uygulanır.

-L. major lezyonlarına 20 gün süresince günde 2 kez topikal paromomycin merhem,

-Kriyoterapi ve IL antimon kombine tedavisi,

-Termoterapi,

-Haftada 2 kez olmak üzere 3-4 hafta süresince İ SbV.

3. Tedavi protokolünde 1 ve 2 'de bulanan ve iyileşmeyen lezyonlarda, çapı $4 \mathrm{~cm}$ veya daha büyük olan lezyonlarda, sayıları 4'ten fazla olan lezyonlarda, lokal tedavi için uygun lokalizasyonda olmayan lezyonlarda, immün sistemi bozuk ve kontrolsüz diyabeti olan hastalarda kontrendikasyon yoksa sistemik SbV tedavisi önerilir.

Pentavalent antimon ilaçları sistemik tedavide parenteral yolla verilirler. Sodium stibogluconate $100 \mathrm{mg} / \mathrm{ml}$, meglumine antimoniate ise $81 \mathrm{mg} / \mathrm{mL} \mathrm{SbV}$ içerir (50). Her iki ilaç için günlük doz $20 \mathrm{mg} / \mathrm{kg} \mathrm{SbV'dir.} \mathrm{Üst} \mathrm{doz} \mathrm{sınırı} \mathrm{yoktur.} \mathrm{Meglumine}$ antimonate IM derin yapılmalı, günlük doz 10 ml'den fazla ise bölünerek iki yerden verilmelidir. Sodium stibogluconate ile IV tedavi daha az ağrılıdır. Günlük doz 50-200 ml \%5 dekstroz solüsyonu içinde 30-60 dakikada gidecek şekilde yavaş infüzyonla veya doğrudan iV yolla 15-20 dakikada verilmelidir. Tedavi süresi 10-20 gündür. Rezidivan ve diffüz $\mathrm{KL}$ tedavisinde sistemik SbV tedavisi standart dozlarda ve daha uzun süreli yapılabilir. Yanıt yoksa tedaviye oral yoldan $20 \mathrm{mg} / \mathrm{kg} / \mathrm{g}$ dozunda allopurinol eklenebilir. Tedavi 30 gün sürdürülmelidir (3).

Kas ve eklem ağrıları (genellikle tedavinin 1. haftasından sonra), halsizlik, iştahsızlık, bulantı, karın ağrısı, baş ağrısı, deri döküntüsü, pankreatik enzimlerde yükselme, transaminazlarda yükselme, hafif lökopeni ve Elektrokardiyografi'de (EKG) nonspesifik ST değişiklikleri en sık görülen istenmeyen reaksiyonlardır (51). Tedaviye başlanmadan ve tedavi sırasında kalp, böbrek, pankreas, karaciğer fonksiyonları ve hematolojik parametreler haftalık izlenmelidir. Karaciğer enzimlerinde (aminotransferazlar) 4 kat artış varsa tedavi kesilmelidir. Serum amilaz değerleri normal üst sınırdan 5 kattan daha fazla, lipaz değerleri ise 15 kattan daha fazla yükselmişse tedaviye ara verilmelidir. EKG ile haftada 2 kez izlem yapılmalıdır. Tedavi sırasında QT intervali yakından izlenmelidir. Düzeltilmiş QT intervali 500 msn'nin üzerine çıktığında tedaviye ara verilmelidir (2). Risk ve faydaları dikkate alındığında pentavalent antimon bileşikleri sistemik olarak sadece şiddetli ve komplike lezyonlarda kullanılmalıdır. Kardiyak, hepatik, pankreatik, hematolojik hastalığı bulunanlarda ve yaşlılarda mortaliteye neden olabilecek toksisite riski yüksek olduğundan, bu olgularda sistemik antimon tedavisi önerilmemektedir. Renal yetmezlikte parenteral antimonialler birikir. Antimon klerens oranı çocuklarda erişkinlere göre daha yüksek olduğu için çocuklarda erişkinlere göre daha düşük tedavi yanıtı alınır, fakat istenmeyen etkiler ise erişkinlerde daha sıktır (52).

Pentavalent antimon bileşiklerine dirençli veya şiddetli yan etkilerin görüldüğü olgularda başta amphotericin $B$ ve miltefosin olmak üzere alternatif ilaçlar da kullanılabilmektedir (49). Amphotericin B'nin yüksek toksisite riskine karşın, pentavalent antimon tedavisine göre daha iyi klinik yanıt ve daha düşük relaps oranları bildirilmiştir. En önemli dezavantajı maliyeti, verilme şekli ve soğuk zincirde stabilitesini koruyabilmesidir (53).

Miltefosin oral alkilleyici antineoplastik bir ajan olup, kutanöz, mukozal ve visseral leishmaniasise karşı aktivite gösterir. ABD'de 2014 yılında mukozal, L. donovaninin neden olduğu visseral ve L. braziliensis, L. guyanensis ve L. panamensisin neden olduğu KL'li 12 yaşın üzerindeki bireylerin tedavisinde Amerikan Gıda ve İlaç Dairesi onayı almıştır. Gebelerde kullanımı kontrendikedir (54).

Azollerin KL'deki etkinliği sınırlı olup, tedavi başarısızlığı sıktır. Günde $200 \mathrm{mg}$ dozunda 8 hafta süreyle oral fluconazol tedavisi L. major olgularında etkili bulunmuştur. Günlük 400 mg fluconazolun günlük 200 mg fluconazole göre daha etkili olduğu bildirilmiştir (55).

KL'de iyileşme yavaş olup, tedaviden sonra da devam eder. Lezyonlar tedavinin sonunda nadiren tam iyileşir. Tedaviye yanıt genellikle klinik görünüme göre değerlendirilir. Tedaviyi izleyen 4-6 haftada lezyon 2/3 oranında küçülmeli, ödem ve inflamasyon düzelmeli, ülser reepitelize olmalı ve yeni lezyonlar gelişmemelidir (56). Ülserlerin reepitelizasyonu veya tam klinik iyileşme genellikle tedaviyi izleyen üç ayda olur. Tedaviden sonra hastalar relaps açısından 6-12 ay süresince izlenmelidir (57). 


\section{Korunma ve Kontrol}

Leishmaniasisin önlenmesi ve kontrol altına alınabilmesi kombine müdahale stratejileri gerektirir. Zoonotik leishmaniasisin kontrolünde rezervuar konakların kontrolü önemli iken, antroponotik leishmaniasiste ise olguların saptanması, sürveyans ve uygun tedavisi önemlidir. Rezervuarlara yönelik olarak yerleşim alanları ve çevresinde kemirgenlerle mücadele edilmelidir. Kemirgen yuvalarının ve beslenme ortamlarının tahrip edilmesi zoonotik KL'nin kontrolünde etkilidir. Ayrıca sokak köpeklerinin veteriner takibi yapılmalı, uygun ürünlerle kum sineklerinden korunmaları sağlanmalıdır $(2,58)$.

Vektör kontrolünde kimyasallar, çevresel iyileştirme ve kişisel korunma gibi kontrol yöntemleri uygulanabilir. Vektör mücadelesinde kum sineklerinin üreme ve gizlenme alanlarının kontrolü ve tahribi oldukça önemlidir. Bu kapsamda; kum sineklerinin gündüzsaklandıkları evlerin, ahırların ve tuvaletlerin duvarlarındaki yarık ve çatlakların sıvanarak onarılması, kireçle badanalanması gereklidir (58). Ayrıca organik atıkların düzenli olarak toplanması ve çimlerin belirli aralıklarla biçilmesi de faydalı olmaktadır. Kimyasal mücadele kapsamında; evlerin, ahırların, hayvan barınaklarının iç ve dış duvarlarına rezidüel insektisitlerle uygulama yapılmalıdır. Vektör-insan ilişkisini kesmek amacıyla özellikle insektisit emdirilmiş cibinlikler ve perdelerin kullanılması etkili olmaktadır. Yine kum sineklerinin aktif olduğu saatlerde dışarı çıkılmaması, uzun kollu giysiler giyilmesi ve sinek kovucu ürünler kullanılması da vektör tarafından ısırılma olasılığını azaltacaktır (59).

Enfeksiyonu geçiren kişiler parazit türüne göre hastalığa karşı hayat boyu bağışıklık kazanırlar. Leishmaniasise karşı kullanılabilecek etkili koruyucu profilaksi veya ticari bir aşı henüz yoktur. Aşı geliştirme çalışmaları devam etmektedir (2).

\section{Yazarlık Katkıları}

Hakem Değerlendirmesi: Editörler kurulu tarafindan değerlendirilmiştir, Çıkar Çatışması: Yazar bu makale ile ilgili olarak herhangi bir çıkar çatışması bildirmemiştir, Finansal Destek: Çalışma için hiçbir kurum ya da kişiden finansal destek alınmamıştır.

\section{Kaynaklar}

1. World Health Organization. Leishmaniasis. (Availableat:http://www.who. int/leishmaniasi/en/.

2. WHO Technical Report Series, 949; Control of theLeishmaniases: report of a meeting of the WHO ExpertCommittee on the Control ofLeishmaniases, Geneva, 22-26 March 2010.

3. WHO Regional Publications, Eastern Mediterranean Series, 35; Manual for case management of cutaneous leishmaniasis in the WHO Eastern Mediterranean Region, 2014.

4. World Health Organization. Leishmaniasis: the disease and its epidemiology. Availableat:http://www.who.int/leishmaniasis/disease_epidemiology/en/.

5. T.C. Sağlık Bakanlığı, Türkiye Halk Sağlı̆ı Kurumu Bulaşıcı Hastalıklar Daire Başkanlığı, 02.01.2014 tarih ve 13588366 sayılı evrak.

6. Yanik M, Gurel MS, Simsek Z, et al. The psychological impact of cutaneous leishmaniasis. Clin Exp Dermatol 2004;29:464-7.

7. Freitas-Junior LH, Chatelain E, Kim HA, et al. Visceral leishmaniasis treatment: What do we have, what do we need and how to deliver it? Int J Parasitol Drugs Drug Resist 2012;2:11-9.

8. Sundar S, Sinha PK, Rai M, et al. Comparison of short-course multidrug treatment with Standard therapy for visceral leishmaniasis in India: an openlabel, non-inferiority, randomised controlled trial. Lancet 2011;377: 477-86.
9. Demirel R, Erdoğan S. Determination of high risk regions of cutaneous leishmaniasis in Turkey using spatial analysis. Turkiye Parazitol Derg 2009;3:8-14.

10. Klaus SN, Frankenburg S, Ingber A. Epidemiology of cutaneous leishmaniasis. Clin Dermatol 1999;17:257-60.

11. Gürel MS, Yeşilova Y, Ölgen MK, ve ark. Türkiye'de kutanöz leishmaniasisin durumu. Türkiye Parazitol Derg 2012;36:121-9.

12. Murray HW, Berman JD, Davies CR, et al. Advances in leishmaniasis. Lancet 2005;366:1561-77.

13. Alvar J, Velez ID, Bern C, et al. Leishmaniasis worldwide and global estimates of its incidence. PLoS One 2012;7:35671.

14. Yemisen $\mathrm{M}$, Ulas $\mathrm{Y}$, Celik H, et al. Epidemiological and clinical characteristics of 7172 patients with cutaneous leishmaniasis in Sanliurfa, between 2001 and 2008. Int J Dermatol 2012;51:300-4.

15. Uzun S, Uslular C, Yucel A, et al. Cutaneous leishmaniasis: evaluation of 3,074 cases in the Cukurova region of Turkey. Br J Dermatol 1999;140:34750.

16. Gurel MS, Ulukanligil M, Ozbilge H. Cutaneous leishmaniasis in Sanliurfa: epidemiologic and clinical features of the last fouryears (1997-2000). Int J Dermatol 2002;41:32-7.

17. Korkmaz S, Özgöztaşı $O$, Kayıran N. Gaziantep üniversitesi tıp fakültesi leishmaniasis tanı ve tedavi merkezine başvuran leishmaniasis olgularının değerlendirilmesi. Turkiye Parazitol Derg 2015;39:13-6.

18. Salman IS, Vural A, Unver A, ve ark. Suriye İ̧̧ Savaşı sonrası Nizip'de Kutanöz Leyşmanyazis Olguları. Mikrobiyol Bul 2014;48:106-13.

19. Demirkan S, Özlü E, Yıldırım Mevlüt. Kutanöz leishmaniasis için endemik bir bölge: Birecik. J Clin Anal Med Published Online. http://www.jcam.com.tr/ files/KATD-3756.pdf.

20. Freedman DO, Weld LH, Kozarsky PE, et al. Spectrum of disease and relation to place of exposure ill returned travellers. N Engl J Med 2006;354:119-30.

21. Lederman ER, Weld LH, Elyazar IR, et al. Dermatologic conditions of the ill returned traveller: an analysis from the GeoSentinel Surveillance Network. Int J Infect Dis 2008:12:593-602.

22. Çulha G, Akçalı C. Hatay ve çevresinde saptanan kutanöz leishmaniasis olguları.Turkiye Parazitol Derg 2006;30:268-71.

23. Sucaklı MB, Saka G. Diyarbakır'da şark çıbanı epidemiyolojisi. Turkiye Parazitol Derg 2007;31:165-9.

24. Ser Ö, Çetin H. Kutanöz leishmaniasis ve Antalya ilindeki durumu. Turkiye Parazitol Derg 2013;37:84-91.

25. Sharma NL, Mahajan VK, Kanga A, et al. Localized cutaneous leishmaniasis due to leishmania donovani and leishmania tropica: preliminary findings of the study of 161 new cases from a new endemic focus in himachal Pradesh, India. Am J Trop Med Hyg 2005;72:819-24.

26. Koltas IS, Eroglu F, Alabaz D, et al. The emergence of leishmania major and Leishmania donovani in southern Turkey. Trans R Soc Trop Med Hyg 2014;108:154-8.

27. Atakan E, Akbaba M, Sütoluk Z, ve ark. Hocallı ve Turunçlu (Adana) köylerinde phlebotomus (Diptera; Psychodidae; Phlebotomine) türlerinin populasyon yoğunluğu ve kutanöz leishmaniasis ile ilişkisi. Turkiye Parazitol Derg 2010;34:106-11.

28. Uzun S, Durdu M, Culha G, et al. Clinical features, epidemiology, and efficacy and safety of intralesional antimony treatment of cutaneous leishmaniasis: recent experience in Turkey. J Parasitol 2004;90:853-9.

29. Bates PA. Transmission of leishmania metacyclic promastigotes by phlebotomine sand flies. Int J Parasitol 2007;37:1097-106.

30. ul Bari A. Epidemiology of cutaneous leishmaniasis. J Pak Assoc Dermatol 2006;16:156-62.

31. Douba MD, Abbas O, Wali A, et al. Chronic cutaneous leishmaniasis, a great mimicker with various clinical presentations: 12 years experience from Aleppo. J Eur Acad Dermatol Venerreol 2012;26:1224-9.

32. Culha G, Uzun S, Ozcan K, et al. Comparison of conventional and polymerase chain reaction diagnostic techniques for leishmaniasis in the endemic region of Adana, Turkey. Int J Dermatol 2006;45:569-72.

33. Sellheyer K, Haneke E. Protozoan diseases and parasitic infestations. In: Elder DE, editor. Lever's histopathology of the skin. 9th ed. Philadelphia: Lippincott; 2005. p.635-9.

34. T.C. SağlıkBakanlığı, Türkiye Halk Sağlığı Kurumu, ulusal mikrobiyoloji standartları, şark çıbanının mikrobiyolojik tanısı 2015.

35. Hodiamont $C R$, Kager PA, Bart A, et al. Species-directed therapy for leishmaniasis in returning travellers: a comprehensive guide PLoS Negl Trop Dis 2014;8:2832. 
36. Morizot G, Kendjo E, Mouri O, et al. Travellers with cutaneous leishmaniasis cured without systemic therapy. Clin Infect Dis 2013;57:370-80.

37. Minodier P, Parola P. Cutaneous leishmaniasis treatment. Travel Med Infect Dis 2007;5:150-8.

38. Harman M. Layşmanyasis kutis tedavisi. Tuzun $\mathrm{Y}$, Serdaroğlu S, editorler. Dermatolojide gelişmeler-8. İstanbul: Umur Basım ve Kırtasiye San. Ve Tic.A.Ş 2009. p.32-5.

39. Munir A, Janjua SA, Hussain I. Clinical efficacy of intramuscular meglumine antimoniate alone and in combination with intralesional meglumine antimoniate in the treatment of old world cutaneous leishmaniasis. Acta Dermatovenerol Croat 2008;16:60-4.

40. Mohammadzadeh M, Behnaz F, Golshan Z. Efficacy of glucantime for treatment of cutaneous leishmaniasis in Central Iran. J Infect Public Health 2013;6:120-4.

41. Yesilova Y, Surucu HA, Ardic N, et al. Meglumine antimoniate is more effective than sodium stibogluconate in the treatment of cutaneous leishmaniasis. J Dermatolog Treat 2015:1-5.

42. Salmanpour R, Razmavar MR, Abtahi N. Comparison of intralesional meglumine antimoniate, cryotherapy and their combination in the treatment of cutaneous leishmaniasis. Int J Dermatol 2006;45:1115-6.

43. Layegh $P$, Pezeshkpoor $F$, Soruri $A H$, et al. Efficacy of cryotherapy versus intralesional meglumine antimoniate (glucantime) for treatment of cutaneous leishmaniasis in children. Am J Trop Med Hyg 2009;80:172-5.

44. al-Majali O, Routh HB, Abuloham O, et al. A 2-year study of liquid nitrogen therapy in cutaneous leishmaniasis. Int J Dermatol 1997;36:460-2.

45. Sadeghian G, Nilfroushzadeh MA, Iraji F. Efficacy of local heat therapy by radiofrequency in the treatment of cutaneous leishmaniasis, compared with intralesional injection of meglumine antimoniate. Clin Exp Dermatol 2007;32:371-4.

46. López $L$, Robayo M, Vargas $M$, et al. Thermotherapy. An alternative for the treatment of American cutaneous leishmaniasis. Trials 2012;13:58.

47. Asilian A, Davami M. Comparison between the efficacy of photodynamic therapy and topical paromomycin in the treatment of Old World cutaneous leishmaniasis: a placebo-controlled, randomized clinical trial. Clin Exp Dermatol 2006;31:634-7.
48. Shani-Adir A, Kamil S, Rozenman D, et al. Leishmania tropica in northern Israel: a clinical overview of an emerging focus. J Am Acad Dermatol 2005;53:810-5.

49. El-On J, Livshin R, Even-Paz Z, et al. Topical treatment of cutaneous leishmaniasis. J Invest Dermatol 1986;87:284-8.

50. Soto J, Valda-Rodriquez L, Toledo J, et al. Comparison of generic to branded pentavalent antimony for treatment of new world cutaneous leishmaniasis. Am J Trop Med Hyg 2004; 71:577-81.

51. Oliveira LF, Schubach AO, Martins MM, et al. Systematic review of the adverse effects of cutaneous leishmaniasis treatment in the New World. Acta Trop 2011;118:87-96.

52. Cruz A, Rainey PM, Herwaldt BL, et al. Pharmacokinetics of antimony in children treated for leishmaniasis with meglumine antimoniate. J Infect Dis 2007; 195:602-8

53. Solomon M, Pavlotzky F, Barzilai A, et al. Liposomal amphotericin B in comparison to sodium stibogluconate for Leishmania braziliensis cutaneous leishmaniasis in travellers. J Am Acad Dermatol 2013;68:284-9.

54. Sindermann $\mathrm{H}$, Engel J. Development of miltefosine as an oral treatment for leishmaniasis. Trans R Soc Trop Med Hyg 2006;100(Suppl 1):17-20.

55. Emad M, Hayati F, Fallahzadeh MK, et al. Superior efficacy of oral fluconazole $400 \mathrm{mg}$ daily versus oral fluconazole $200 \mathrm{mg}$ daily in the treatment of cutaneous leishmania major infection: a randomized clinical trial. J Am Acad Dermatol 2011;64:606-8.

56. Murray HW. Leishmaniasis in the United States: treatment in 2012. Am JTrop Med Hyg 2012;86:434-40.

57. González U, Pinart M, Rengifo-Pardo $M$, et al. Interventions for American cutaneous and mucocutaneous leishmaniasis. Cochrane Database Syst Rev 2009:CD004834.

58. Yaman M. Tatarcıklarla mücadele ve bu alandaki son gelişmeler. Turkiye Parazitol Derg 2008;32:280-7.

59. Claborn DM. The biology and control of leishmaniasis vectors. J Glob Infect Dis 2010;2: 127-34. 


\section{Sorular}

1. Kutanöz leishmaniasisin vektörü ile ilgili olarak aşağıdakilerden hangisi doğrudur?
a) Vektör dişi kum sinekleridir
b) Gündüzleri aktiftirler
c) Beslenmek için kilometrelerce uçabilirler
d) Sadece insan kanı ile beslenirler
e) Normal sivrisinek cibinliklerinden geçmezler

2. Aşağıdakilerden hangisi kutanöz leishmaniasisin yayılmasında rol oynamaz?
a) İklim değişiklikleri
b) Savaşlar
c) Doğal afetler
d) Kırsal alanlardan şehirlere göç
e) Planlı şehirleşme

3. Türkiye'de kutanöz leishmaniasise en sık hangisi neden olur?
a) L. tropica
b) L. infantum
c) L. majör
d) L. donovani
e) L. chagasi
4. Yaş tip kutanöz leishmaniasise hangisi neden olur?
a) L. infantum
b) L. braziliensis
c) L. majör
d) L. aethiopica
e) L. tropica
5. Aşağıdakilerden hangisi L. tropica'nın ana rezervuarıdır?
a) Köpek
b) Kemirgen
c) Insan
d) Kum sineği
e) Hyrax

6. Kutanöz leishmaniasisde aşağıdaki lezyonların hangisinde amastigotları saptamak en kolaydır?
a) Papül
b) Krutlu nodül
c) Kronik lezyon
d) Sekonder enfekte plak
e) Rezidivan papül

7. Aşağıdakilerden hangisi kutanöz leishmaniasis tanısını doğrulamada en sık kullanılan tanısal yöntemdir?
a) Kültür
b) Lezyondan hazırlanan yaymaların mikroskobik muayenesi
c) Biyopsi yapılarak histopatolojik inceleme
d) Serolojik tetkik
e) PCR

8. Kutanöz leishmaniasisde tedavi ile ilgili olarak aşağıdakilerden hangisi doğrudur?
a) Her hasta tedavi edilmelidir b) Tedavide en sık pentavalent antimon bileşikleri
kullanımaktadır
c) Sistemik tedavi tercih edilmelidir
d) Tedavide kullanılan ilaçlar güvenlidir
e) Komplike olgularda IL antimon tedavisi tercih edilmelidir

9. Aşağıdakilerden hangisi kutanöz leishmaniasisin önlenmesi ve kontrol altına alınmasında etkili değildir?
a) Vektörle mücadele
b) Hastaların tedavi edilmesi
c) Rezervuarların kontrolü
d) Hastalarla temastan kaçınma
e) Planlı kentleşme ve sağlıkı konutlar

10. Türkiye'de son yıllarda yaş tip kutanöz leishmaniasis olgularında artış görülmesinin temel nedeni aşağıdakilerden hangisidir?
a) Tatarcıklarla yeterli mücadele yapılmaması
b) İklim ve çevre değişiklikleri
c) Kırsal alanlardan şehirlere göç
d) Özellikle Suriye'den Türkiye'ye olan mülteci akını
e) Hastaların saptanması amacıyla tarama yapılmaması 